\title{
Temperature regulation and microhabitat choice by free-ranging Galapagos fur seal pups (Arctocephalus galapagoensis)
}

\author{
Dominique Limberger, Fritz Trillmich, Herbert Biebach, and Robert D. Stevenson \\ Max-Planck-Institut für Verhaltensphysiologie, D-8131 Seewiesen, Federal Republic of Germany
}

\begin{abstract}
Summary. Behavioural activity, and core and surface temperatures of 4 unrestrained Galapagos fur seals were recorded in the natural habitat during their first weeks of life. Climatic variables were registered simultaneously. Pup behaviours were divided into bouts of resting ( $55 \%$ of total time), sucking ( $23 \%)$ and other activities $(22 \%)$. Pups maintained a constant body temperature from their first day. Core temperature $\left(T_{\mathrm{c}}\right)$ was $37.7^{\circ} \mathrm{C} \pm 0.3^{\circ} \mathrm{C}(\bar{x} \pm \mathrm{SD})$ over 39 pup-days and 8 pup-nights. Skin temperature was correlated with $T_{\mathrm{c}}$, but flipper temperature was not. No daily $T_{c}$ rhythm was detected. Microclimate data were used to calculate operative temperature $T_{\mathrm{e}}$. Environmental temperatures can be very high, with $T_{\mathrm{e}}$ above $T_{\mathrm{c}} 6-9 \mathrm{~h}$ a day for animals exposed to the sun, but below it in the shade. $T_{\mathrm{e}}$ is about $22^{\circ} \mathrm{C}$ at night. Pups avoid overheating mainly by withdrawing into the shade and reducing activity to a minimum during the hot hours of the day. Sun-exposed pups could be active at any time during the day if they had access to water, which was usually around high tide.
\end{abstract}

Pinnipeds show a high degree of aquatic specialisation, yet all species spend some time on land. They maintain a relatively constant body temperature in both environments, even though the thermal fluxes are tremendously different. Most studies have investigated physiological adaptations to cold environments (Blix and Steen 1979; Elsner et al. 1977; Irving et al. 1962; Irving and Hart 1957). They have shown that sophisticated mechanisms for countercurrent heat exchange in the flippers, highly developed insulation and an increased basal metabolic rate permit maintenance of a constant body temperature in water and in very cold terrestrial environments. The latter two characteristics seriously impede thermoregulation on land. Forced activity on land, even in a cool environment, quickly led to overheating in Northern fur seals (Bartholomew and Wilke 1956). Seals have a number of physiological mechanisms to maintain thermal balance (Matsuura and Whittow 1973) but also utilise behavioural ones (Gentry 1972). Avoiding the sun and becoming wet are among the most important of these since physiological mechanisms are insufficent at high temperatures on land (Whittow et al. 1971). Otariid seals are the most terrestrial pinnipeds and the non-migratory Galapagos fur seal (Arctocephalus galapagoensis) may

Offprint requests to: $\mathrm{D}$. Limberger well be the most terrestrial otariid. It spends about $30 \%$ of its adult life ashore on the equator (Trillmich 1984), and thus may experience the greatest solar heat load of any seal.

This study describes the microclimate experienced by Galapagos fur seal pups, which live exclusively on land in the first few weeks, and documents how they cope with the extremely hot environment.

Male Galapagos fur seals defend territories; females come ashore and pup on a narrow coastal zone about $20 \mathrm{~m}$ wide, parallel to the waterline. Pupping occurs from August to November, with a peak in late September/early October (Trillmich 1984). This coincides with the Galapagos cool season which lasts from June to December. Steady SE winds are associated with the intense upwelling of cool $\left(\mathrm{ca} .18^{\circ} \mathrm{C}\right)$ waters at this time. Coastal rainfall is low but light cloud cover around the larger islands usually reduces the solar radiation load for part of the day (details on the Galapagos climate in Colinvaux 1984).

\section{Material and methods}

Study site

The investigation was performed in 1979,82 and 83 at Cabo Hammond on Fernandina $\left(91^{\circ} \mathrm{W}, 0^{\circ} 28^{\prime} \mathrm{S}\right)$, the westernmost island of the Galapagos archipelago. The island shoreline consists partly of lava flows and partly of boulders rounded by wave action. All observations were carried out within a $650 \mathrm{~m}$ section of the fur seal colony.

\section{Data collection}

General observations on pups. Galapagos fur seals can be approached closely without being disturbed. Pups were individually marked by cutting symbols in the fur on their backs. Hourly checks were made in a $30 \mathrm{~m}$ subsection of the colony from September 1-October 13, 1982. The pups' location, behaviour, degree of wetness, exposure to solar radiation and the presence or absence of the mother were noted. An average of more than $80 \%$ of the 11 pups in the study site were encountered in each survey. Even at noon when pups withdrew underneath stones or into caves an average of $75 \%$ were found.

Observations on pups equipped with temperature transmitters. Temperature sensitive transmitters (Minimitter in 1979 and 
Table 1. Pups used in temperature telemetry. Total observation time: days (daylight hours only) $448.5 \mathrm{~h}$, night $77 \mathrm{~h}$. Growth rate calculated over the first 10 days of life

\begin{tabular}{|c|c|c|c|c|c|c|}
\hline \multirow[t]{2}{*}{ Sex } & \multirow[t]{2}{*}{ Code } & \multirow[t]{2}{*}{ Birth date } & \multicolumn{2}{|c|}{ Observed } & \multirow{2}{*}{$\begin{array}{l}\text { Birth } \\
\text { weight } \\
\text { (kg) }\end{array}$} & \multirow{2}{*}{$\begin{array}{l}\text { Growth } \\
\text { rate } \\
(\mathrm{g} / \mathrm{d})\end{array}$} \\
\hline & & & days & nights & & \\
\hline q & 79 & 17.10 .79 & 7 & 2 & 3.8 & 46.0 \\
\hline q & $\mathrm{NB}$ & 21. 9.83 & 12 & 3 & 3.2 & 75.0 \\
\hline$\delta$ & TA & 27.9 .83 & 6 & 1 & 3.2 & 76.9 \\
\hline q & $X$ & 4.10 .83 & 14 & 2 & 3.4 & 63.6 \\
\hline
\end{tabular}

KT80, Austec Electronics in 1983) were force fed to the pups (Table 1) and remained in their stomachs. Calibration curves were established in a waterbath in the laboratory and reconfirmed before transmitter use. The signals were received with a whip antenna (1979) and an H-shaped antenna (1983). Pulse intervals were read from the digital display of the receiver (Burchard, FRG, West Germany in 1979 and Austec Electronics, Canada in 1983).

All pups chosen for telemetry were in good condition, with normal birth weights and growth rates (Table 1) (cf. Trillmich and Limberger 1985). The behaviour of their mothers also appeared typical. Observations were made sitting next to the pup, each observer taking a $2-4 \mathrm{~h}$ shift. Core temperature $\left(T_{\mathrm{c}}\right)$ and behaviour were registered every $2 \mathrm{~min}$. Behaviour was assigned to the categories: lying down, sitting, moving and unknown, with specifications such as calling, playing and sucking. The positions of the pup's flippers were noted, as was an estimate of the percentage (in 10\% steps) of its body which was (1) exposed to the sun and (2) wet. Protocols also included the female's behaviour (Limberger, in prep).

Temperature of the skin between the scapulars $\left(T_{\mathrm{s}}\right)$ was taken at less regular intervals in 1979. The sensor $\operatorname{rod}(d=$ $0.55 \mathrm{~mm}$ ) was placed through the fur resting on the underlying skin and a uniform pressure of $16 \cdot 10^{3}$ Pascal applied. Values were read from a fast responding digital thermome- ter (Testoterm, W-Germany). Surface temperature of fur $\left(T_{\mathrm{fur}}\right)$ and the flippers $\left(T_{\mathrm{f}}\right)$ were measured using an infra-red thermometer (KT15, Heimann GmbH, W-Germany). The lens was held at right angles to and no more than $50 \mathrm{~cm}$ from the measured surface. This resulted in a field of measurement $30 \mathrm{~mm}$ in diameter. Whether the area was wet or dry, exposed or shaded was also noted.

Climatic variables. Environmental data were recorded for each hour. If not stated else, mean \pm one standard deviation $(\bar{x} \pm \mathrm{SD})$ are given.

Measurements in 1979 and 1982 were taken at two different locations within the study site which were representative of two extreme microhabitats available to the pups: (1) an area exposed to solar radiation and (2) inside a lava tunnel frequently visited by pups. Environmental data were recorded from the immediate surroundings of studied animals in 1983.

Air temperature $\left(T_{\mathrm{a}}\right)$ and wind velocity $(\bar{v})$ were measured approximately $30 \mathrm{~cm}$ above ground with a fast responding digital instrument (Testovent 4000, Testoterm, WGermany). The temperature sensor was shaded. Ground temperature $\left(T_{\mathrm{g}}\right)$ was sometimes measured with the sensor rod used for taking $T_{s}$, but usually with permanently attached thermocouples (Ni-CR-Ni, Testoterm type 0644.160). Shortwave radiation measurements were made only in 1979, with the radiometer sensor (Li-Cor, Li-170; Lambda Inst. Corp.) pointing towards the sun. Values were corrected for to approximate global radiation values (GR), equivalent to total shortwave radiation measured on a horizontal surface (Gates 1981). The degree of cloudiness was estimated and assigned to the categories cloudless, thin cloud layer (sun still visible) and cloudy.

Behaviour, $T_{\mathrm{c}}, T_{\mathrm{a}}$ and occasionally $T_{\mathrm{g}}$ were noted during the 8 night protocols; (during the night of October $18 / 19,1979$ recordings were less frequent, intervals varying between 5 and $30 \mathrm{~min}$ ).

Operative environmental temperature, the effective temperature of the environment as perceived by the animal, was calculated using Bakken's (1976) equation (12):

Table 2. Climatic variables at pup height for day and night. Air temperature $\left(T_{a},{ }^{\circ} \mathrm{C}\right)$, wind velocity $(\bar{v}$, m/s), ground temperature $\left(T_{\mathrm{g}},{ }^{\circ} \mathrm{C}\right)$ on an exposed and a sheltered site and global radiation $\left(\mathrm{GR}, \mathrm{W} / \mathrm{m}^{2}\right)$

\begin{tabular}{|c|c|c|c|c|c|c|c|c|c|c|c|c|c|c|}
\hline \multirow{2}{*}{$\begin{array}{l}\text { Time } \\
\text { of day } \\
\text { (h) }\end{array}$} & \multicolumn{3}{|c|}{$T_{\mathrm{a}}\left({ }^{\circ} \mathrm{C}\right)$} & \multicolumn{3}{|c|}{$\bar{v}(\mathrm{~m} / \mathrm{s})$} & \multicolumn{6}{|c|}{$T_{\mathrm{g}}\left({ }^{\circ} \mathrm{C}\right)$} & \multicolumn{2}{|c|}{$\mathrm{GR}\left(\mathrm{W} \mathrm{m} \mathrm{m}^{-2}\right)$} \\
\hline & $\bar{x}$ & SD & $N$ & $\bar{x}$ & $\mathrm{SD}$ & $N$ & \multicolumn{3}{|c|}{ exposed } & \multicolumn{3}{|c|}{ sheltered } & $\bar{x}$ & $N$ \\
\hline 6 & 21.9 & 0.9 & 31 & 0.8 & 0.6 & 32 & 21.9 & 1.3 & 24 & 23.1 & 0.6 & 7 & 18 & 5 \\
\hline 7 & 22.8 & 0.9 & 37 & 1.0 & 0.6 & 38 & 24.2 & 1.9 & 27 & 24.2 & 0.9 & 7 & 141 & 7 \\
\hline 10 & 26.3 & 2.3 & 39 & 1.0 & 0.5 & 46 & 39.1 & 6.8 & 36 & 28.1 & 1.2 & 11 & 724 & 7 \\
\hline 11 & 27.0 & 2.4 & 40 & 1.2 & 0.5 & 46 & 43.5 & 6.5 & 36 & 29.2 & 1.1 & 11 & 804 & 8 \\
\hline 12 & 27.4 & 2.6 & 41 & 1.3 & 0.7 & 47 & 46.4 & 6.3 & 37 & 29.8 & 1.1 & 12 & 1006 & 7 \\
\hline 13 & 27.4 & 3.2 & 39 & 1.5 & 0.7 & 47 & 47.1 & 6.8 & 35 & 30.7 & 0.7 & 11 & 910 & 7 \\
\hline 14 & 27.0 & 3.3 & 39 & 1.5 & 0.8 & 46 & 45.3 & 6.7 & 35 & 30.4 & 0.7 & 13 & 739 & 6 \\
\hline 15 & 27.0 & 2.9 & 38 & 1.4 & 0.7 & 47 & 40.9 & 6.5 & 36 & 29.7 & 1.0 & 11 & 686 & 6 \\
\hline 16 & 25.8 & 2.6 & 38 & 1.3 & 0.7 & 46 & 36.7 & 4.9 & 34 & 29.1 & 0.7 & 11 & 443 & 5 \\
\hline
\end{tabular}


Table 3. Hourly means of net radiation $\left(Q_{n}\right)$ and overall surface temperature $\left(\bar{T}_{\mathrm{r}}\right)$ for exposed and sheltered pups used for computing $T_{\mathrm{e}}$ [Bakken 1976, Eq. (12)]

\begin{tabular}{|c|c|c|c|}
\hline \multirow{2}{*}{$\begin{array}{l}\text { Time } \\
\text { of day } \\
\text { (h) }\end{array}$} & \multicolumn{2}{|l|}{$\bar{T}_{\mathrm{r}}\left({ }^{\circ} \mathrm{C}\right)$} & \multirow{2}{*}{$\begin{array}{l}Q_{\mathrm{n}} \\
\left(\mathrm{W} \mathrm{m}^{-2}\right.\end{array}$} \\
\hline & exposed & sheltered & \\
\hline 6 & 29.0 & 28.6 & 3.9 \\
\hline 7 & 31.7 & 30.5 & 135.8 \\
\hline 8 & 33.0 & 32.3 & 225.4 \\
\hline 9 & 34.0 & 33.4 & 268.8 \\
\hline 10 & 37.3 & 34.5 & 289.8 \\
\hline 11 & 38.3 & 36.4 & 300.2 \\
\hline 12 & 42.4 & 37.3 & 303.4 \\
\hline 13 & 42.3 & 33.0 & 229.0 \\
\hline 14 & 42.2 & 33.0 & 268.9 \\
\hline 15 & 36.1 & 32.8 & 265.0 \\
\hline 16 & 32.4 & 32.5 & 214.4 \\
\hline 17 & 29.9 & 29.2 & 110.0 \\
\hline 18 & 29.1 & 28.9 & 0.0 \\
\hline night & 25.0 & 25.0 & 0.0 \\
\hline
\end{tabular}

$$
T_{\mathrm{e}}=\frac{K_{\mathrm{sf}} \cdot\left(H \cdot T_{\mathrm{a}}+R \cdot \widetilde{T}_{\mathrm{r}}+Q_{\mathrm{n}}+G \cdot T_{\mathrm{g}}\right)+G \cdot T_{\mathrm{g}} \cdot(H+R)}{\left(K_{\mathrm{sf}}+G\right) \cdot(H+R)+G \cdot K_{\mathrm{sf}}} .
$$

$T_{\mathrm{e}}$ was calculated for dry pups resting with their flippers tucked in. It was estimated that $30 \%$ of the body surface was in contact with the ground. The following additional assumptions were made:

$K_{\text {sf }}\left(\mathrm{W} / \mathrm{m}^{2} \cdot{ }^{\circ} \mathrm{C}\right):$ thermal conductance of skin and fur layer combined $=3.3$ (conductivity of fat $=0.205 \mathrm{~W} / \mathrm{m}^{\circ}{ }^{\circ} \mathrm{C}$, conductivity of air $=0.025 \mathrm{~W} / \mathrm{m}^{\circ}{ }^{\circ} \mathrm{C}$; Porter and Gates 1969).

$H \quad\left(\mathrm{~W} / \mathrm{m}^{2} \cdot{ }^{\circ} \mathrm{C}\right):$ convection transfer coefficient $=4.2,10.8$ and 19.6 for wind velocity of $0.1,1.0$ and $3.0 \mathrm{~m} / \mathrm{s}$ (Stevenson 1985).

$T_{\mathrm{a}} \quad\left({ }^{\circ} \mathrm{C}\right)$ air temperature and $T_{\mathrm{g}}\left({ }^{\circ} \mathrm{C}\right)$ ground temperature were measured and hourly means used (Table 2).

$R \quad\left(\mathrm{~W} / \mathrm{m}^{2} \cdot{ }^{\circ} \mathrm{C}\right)$ : radiation transfer coefficient; varying with $\bar{T}_{\mathrm{r}}$ between $4.0\left(20^{\circ} \mathrm{C}\right)$, to $4.4\left(30^{\circ} \mathrm{C}\right)$ and 4.9 $\left(40^{\circ} \mathrm{C}\right)$ (Bakken 1976)

$\left.\bar{T}_{\mathrm{r}} \quad{ }^{\circ} \mathrm{C}\right)$ : overall surface temperature, hourly values are averages of fur and flipper temperatures (Table 3).

$Q_{\mathrm{n}} \quad\left(\mathrm{W} / \mathrm{m}^{2}\right)$ : net radiation (Table 3 ), calculated for clear skies for mid-September at latitude 0 , reflectivity of lava $5 \%$ (Lorenz 1968), absorptivity of fur $87 \%$ (Limberger and Porter in prep.), and $30 \%$ of total surface area exposed to direct beam.

$G \quad\left(\mathrm{~W} / \mathrm{m}^{2} \cdot{ }^{\circ} \mathrm{C}\right):$ conduction transfer coefficient $=1.3$ for dry lava (pups exposed during the day) and 12.6 for wet lava (at night or when pup is sheltered) (Stevenson 1985).

\section{Results}

\section{Climatic setting}

Year to year variation was negligible for most of the environmental variables measured. Only sea surface temperature and cloud cover were significantly higher in 1982 than in the other years. This was due to El Niño, the warm water event well documented as ENSO-83 (Cane 1983, Rasmussen and Wallace 1983). Cloud obscured the sun in $55 \%$ and $50 \%$ of the time in 1979 and 1983 (82 and $361 \mathrm{~h}$, respectively), but $67 \%$ of the time $(434 \mathrm{~h})$ in 1982 . There were also several days with light rain that year, which is rare. In 1979 and 1982 the morning was cloudy more often than the afternoon $\left(\chi^{2}\right.$-test, $\left.P<0.005, n=443\right)$; this is reflected in the relatively low morning values of global radiation measurements (Table 2).

The daily time course of environmental conditions at the colony were typical for that time of year (Table 2).

$T_{\mathrm{a}}$ frequently reached a daytime maximum of $30^{\circ} \mathrm{C}$ $\left(29.3 \pm 1.0,30.0 \pm 2.2\right.$ and $28.0 \pm 2.0^{\circ} \mathrm{C}$; for the 3 years $)$. At night it gradually decreased to about $20^{\circ} \mathrm{C}$. The mean and variance were the same on the exposed site and in the shade ( $t$-test, $P>0.9, n=48 ;$ H-test, $P>0.05, n=48$ ).

The black, porous lava is an almost perfect black body with high absorption and low reflectance. It reached $50^{\circ} \mathrm{C}$ in 15 out of 34 days, whereas $T_{\mathrm{g}}$ in the shade only ever approached air temperature, reaching a maximum of $33.3^{\circ} \mathrm{C}$.

Wind velocity $(\vec{v})$ in the fur seal habitat between rocks and boulders varied from $0-3.7 \mathrm{~m} / \mathrm{s}$ with a mean of $1.2 \pm 0.7 \mathrm{~m} / \mathrm{s}(n=472)$. It exceeded $1.0 \mathrm{~m} / \mathrm{s}$ in $49 \%$ and $2.0 \mathrm{~m} / \mathrm{s}$ in $7 \%$ of all measurements. Wind velocity was higher in the afternoons ( $t$-test, $P<0.005, n=574$ ).

\section{Behaviour}

Galapagos fur seal pups were almost constantly close to their mothers during their first week. During the day they rested for about $55.3 \%$ of total time, sucked for $22.6 \%$ and were engaged in other activities (e.g. moving about, grooming, playing and social interactions) for $22.1 \%$. This is similar to data found by Arnold and Trillmich (1985). Days were divided into bouts of resting (median $=64 \mathrm{~min}$, $n=116$ ), sucking (median $=22 \mathrm{~min}, n=69$ ) and other activities (median $=32 \mathrm{~min}, n=136$ ). Activity bouts longer than 100 min (excluding sucking) only occurred during the day when pups became wet (sign test, $P<0.01, n=14$ ). Although very young pups do not enter the sea, they may get wet at any age by the incoming tide. Fermales spend the night inland but when it is hot they move the short distance, usually less than $20 \mathrm{~m}$, to the waterline to cool off in tide pools. They usually drag their pups along on these thermoregulatory moves, at least in the first few days after pupping. Pups were wet for, on average, about $3 \mathrm{~h} /$ day during their first week (median=194 min, 33 events for 7 pups).

Sucking time was reduced to $12 \%$ during the night and other activities filled $35 \%$ of the time. Medians of behaviour bout durations were longer during the night: $94 \mathrm{~min}$ for resting $(n=14), 28 \mathrm{~min}$ for sucking $(n=15)$ and $38 \mathrm{~min}$ for other activities $(n=13)$.

Pups older than 10 days, whose mothers were present, spent less of the day resting $(39.5 \%)$ and sucking $(13.8 \%)$ and thus more in other activities $(46.6 \%)$.

\section{Core temperature}

Core temperature $\left(T_{c}\right)$ remained very stable throughout the day (Fig. 1), with a mean of $37.7 \pm 0.3^{\circ} \mathrm{C}$ (39 pup-days). It varied between a maximum of 39.8 and a minimum of $36.3^{\circ} \mathrm{C}$. The average difference between maximum and 


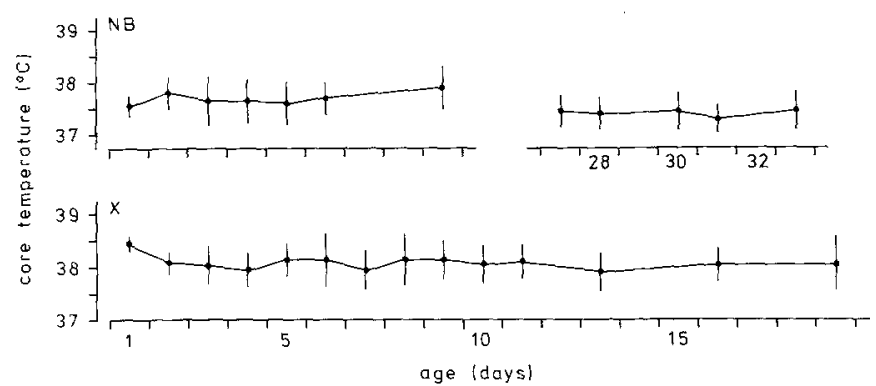

Fig. 1. Daily means and standard deviations of core temperature $\left(T_{c}\right)$ were constant for 2 pups from their first day onwards. Based on 2 min interval records. Pup code as in Table 1

minimum $T_{\mathrm{c}}$ during the day was $1.5^{\circ} \mathrm{C}$. Daily maximal range of $T_{c}$ did not decrease with age. The regression coefficient for the maximal excursion of $T_{\mathrm{c}}$ against age was 0.04 over the first 6 days of life (data from all pups); it was -0.009 for pup NB $(n=12)$ and 0.0003 for pup X $(n=13)$. Day to day variation in average $T_{\mathrm{c}}$ is not very large, as shown in Fig. 1 for pups NB and $X$ whose $T_{\mathrm{c}}$ 's were recorded beyond an age of 10 days.

$T_{\mathrm{c}}\left(37.5 \pm 0.2^{\circ} \mathrm{C}, n=8\right)$ at night did not differ from that of the day (Fig. 2). The mean $T_{\mathrm{c}}$ of an observed night was compared with an average of those for the day preceding and that following it ( $t$-test for matched pairs, $P>0.6, n=$ 16). The variance in $T_{\mathrm{c}}$, however, was larger during the day (F-test, $P<0.001, n=16$ ).

$T_{\mathrm{c}}$ was sensitive to changes in pup activity. It increased in dry pups during the $30 \mathrm{~min}$ following the onset of an activity bout, i.e. activity after resting or sucking not interrupted by more than 5 values of either behaviour (sign test, $P<0.01, n=18$ ). When more than $20 \%$ of a pup's total surface was wet, $T_{\mathrm{c}}$ decreased during the 20 min following the onset of resting (sign test, $P<0.01, n=39$ ). If the pup's behaviour was not taken into account, wetting had no consistent influence on $T_{\mathrm{c}}$.

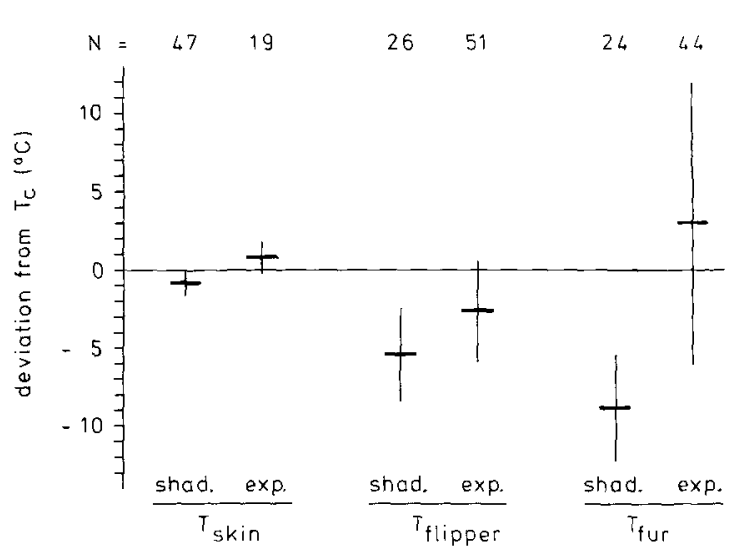

Fig, 3. Comparisons of deviations (mean $\pm S D$ ) of skin, flipper and fur temperatures from simultaneously measured core temperature $\left(T_{c}\right)$ for exposed and shaded pups. $T_{\text {skin }}$ measured in 1979, $T_{\text {flipper }}$ and $\mathrm{T}_{\mathrm{fur}}$ in 1983. Positive deviations indicate that temperatures were higher than $T_{\mathrm{c}}$

\section{Temperatures measured simultaneously for various parts of the body}

Temperatures taken simultaneously from the core $\left(T_{\mathrm{c}}\right)$, skin $\left(T_{\mathrm{s}}\right)$, flippers $\left(T_{\mathrm{f}}\right)$ and fur $\left(T_{\mathrm{fur}}\right)$ (all dry) were compared to examine their relative importance to the pups' heat balance (Fig. 3). $T_{\mathrm{c}}$ was the most stable, $T_{\mathrm{s}}$ showed a slightly higher variance (F-test, $P<0.001, n=130$ ), followed by $T_{\mathrm{f}}$. Variance in $T_{\text {fur }}$ was extreme. $T_{s}$ was very close to $T_{c}$ : it was on average lower in the shade and a little higher when exposed (maximum difference: $3.3^{\circ} \mathrm{C}$ ). $T_{\mathrm{s}}$ was positively correlated with $T_{\mathrm{c}}$ when the pup was exposed to the sun $(r=0.4313, P<0.05, n=19)$, but not when shaded $(r=0.17$, $P>0.1, n=47)$.

$T_{\text {fur }}$ (Fig. 3) reached $61^{\circ} \mathrm{C}$ in exposed pups. It was maximally $23^{\circ} \mathrm{C}$ higher than $T_{\mathrm{c}}$ in sun-exposed and $13.6^{\circ} \mathrm{C}$ below $T_{\mathrm{c}}$ in shaded pups. Wet fur was $33^{\circ} \mathrm{C}$ when the pup was exposed. The pups' fur provided extremely good insula-

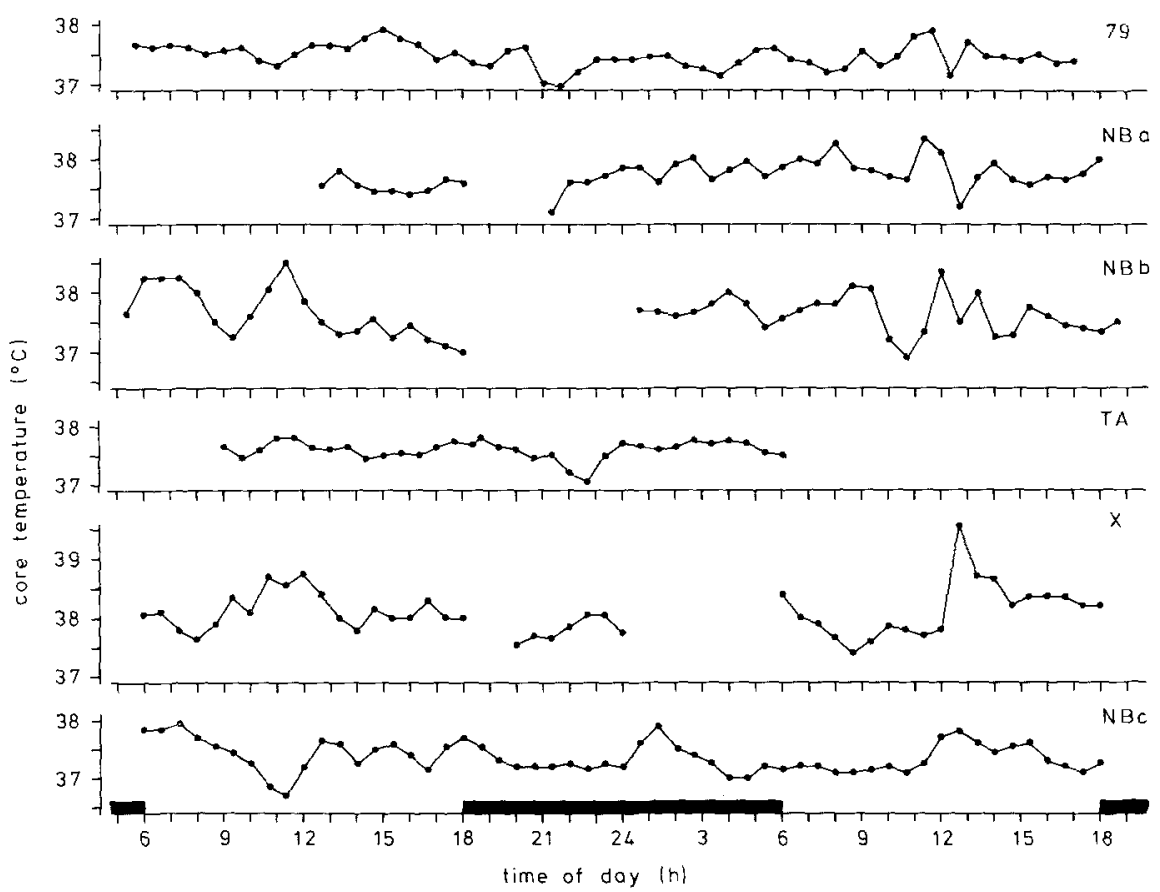

Fig. 2. Daily variation in core temperature $\left(T_{\mathrm{c}}\right)$ averaged over $40 \mathrm{~min}$ intervals for 6 nights and the preceding and following days. There was no daily $T_{\mathrm{c}}$ rhythm. Solid bar on abscissa indicates $\mathrm{h}$ of darkness. Age of pups (code in Table 1) in days: $79=4$ and $5 ; \mathrm{NB}=$ a) 1 and 2, b) 3 and $4, c) 31$ and $32 ; \mathrm{TA}=2$ and $3 ; \mathrm{X}=5$ and 6 

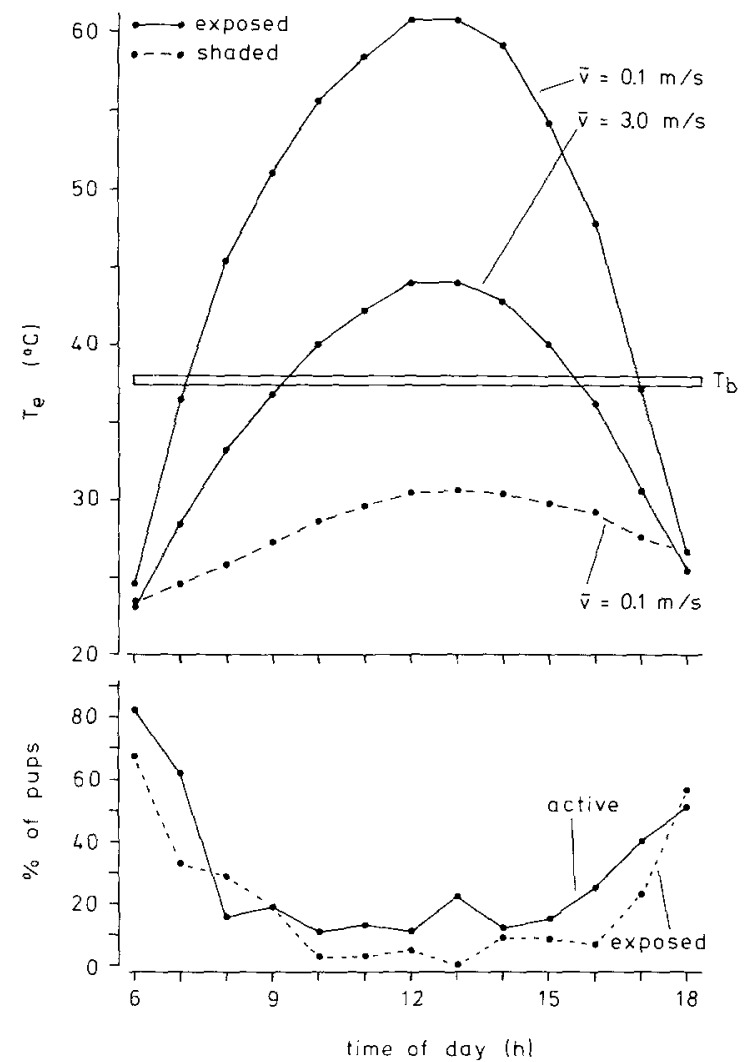

Fig. 4. Upper panel: Daily pattern of operative temperatures $\left(T_{\mathrm{e}}\right)$ for 3 sets of environmental conditions: exposed to full sunlight, $\bar{v}=0.1 \mathrm{~m} / \mathrm{s}$; exposed to full sunlight, $\bar{v}=3.0 \mathrm{~m} / \mathrm{s}$; in a damp cave, $\bar{v}=0.1 \mathrm{~m} / \mathrm{s} . T_{\mathrm{b}}=T_{\mathrm{c}} \pm \mathrm{SD} . T_{\mathrm{e}}$ in the sun exceeds $T_{\mathrm{b}}$ for $6-9 \mathrm{~h}$ per day. Lower panel: percent of lone pups with dry coats. Pups seek shaded places and reduce activity when $T_{e}$ exceeds $T_{b}$. Lone pups were chosen to cancel out the mothers' influence on the pups' behaviour, e.g. via nursing (Limberger in prep)

tion, as seen from the insensitivity of skin temperature to changes in fur temperature: the maximum difference was $20^{\circ} \mathrm{C}$.

Temperatures of the flippers were almost always lower than $T_{\mathrm{c}}$, even during exposure to sun (Fig. 3). $T_{\mathrm{f}}$ was maximally $6.7^{\circ} \mathrm{C}$ higher than $T_{\mathrm{c}}$ for sun exposed flippers and $16.5^{\circ} \mathrm{C}$ below $T_{c}$ when the flippers were shaded. Flippers were significantly cooler in the shade than in the sun ( $t$-test, $P<0.001, n=77)$ and $T_{\mathrm{f}}$ did not correlate with $T_{\mathrm{c}}$ either in the sun $(r=0.113, P>0.1, n=51)$ or the shade $(r=0.118$, $P>0.1, n=24)$.

\section{Pups behavioural responses to operative temperature}

The operative temperature concept has proven useful for quantifying the thermal environment in field studies of other mammals (Bennett et al. 1984, Chappell and Bartholomew 1981). The daily range of operative temperature $\left(T_{\mathrm{e}}\right)$ in the sun was defined by the extremes of wind velocity (Fig. 4, upper panel). It had a range of about $30^{\circ} \mathrm{C}$ during the hot hours of the day. At dawn and dusk this was reduced to about $1.5^{\circ} \mathrm{C}$. $T_{\mathrm{e}}$ of pups exposed to full sunlight exceeded body temperature 6-9 h a day. It became as high as $50^{\circ} \mathrm{C}$ at an average $\bar{v}$ of $1.0 \mathrm{~m} / \mathrm{s}$ and even reached $61^{\circ} \mathrm{C}$ at the low $\bar{v}$ of $0.1 \mathrm{~m} / \mathrm{s}$. A high $\bar{v}$ of $3.0 \mathrm{~m} / \mathrm{s}$ reduced maximal $T_{\mathrm{e}}$ to about $44^{\circ} \mathrm{C}$. $T_{\mathrm{e}}$ remained below body temperature and only reached $31^{\circ} \mathrm{C}$ in caves, which were often wet.

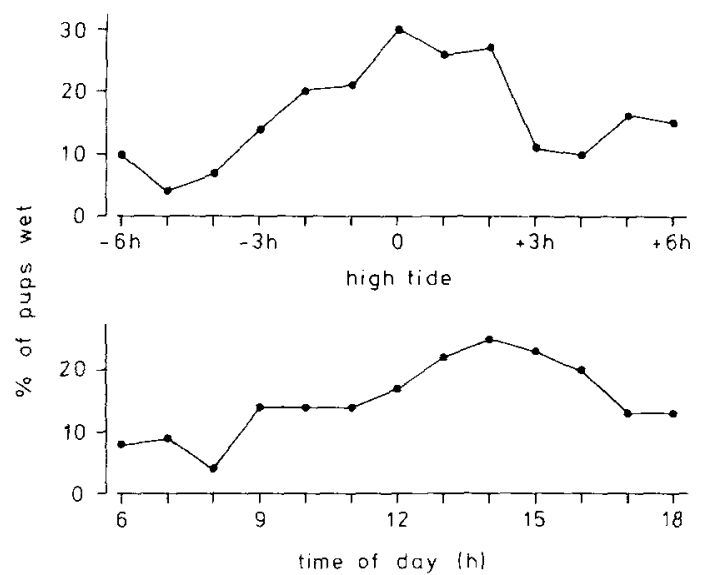

Fig. 5. Percent of wet pups in relation to high tide (upper panel) and to time of day (lower panel). All pups encountered at hourly checks with $>20 \%$ of their body surface wet as percent of total pups encountered. Number of pups per daytime hour always $>12$ and in $75 \%$ of the hours $>20$. Hour of high tide was taken from tide tables for Baltra Island, Galapagos

During the night, when rocks were damp, it was about $22^{\circ} \mathrm{C}$ at an average wind velocity of $1.0 \mathrm{~m} / \mathrm{s}$.

Pups adjusted their behaviour to their physical environment (Fig. 4, lower panel). They reduced their activity during the hot hours of the day, withdrawing into the shade, underneath stones or into lava tunnels. Wetting was only used to a limited degree, as young pups depended on the incoming flood for access to water (Fig. 5). Nevertheless, more wet pups were observed during the hottest hours of the afternoon (Fig. 5, below). Only older fur seal pups went into open water to cool down.

\section{Discussion}

Galapagos fur seal pups are born during the Galapagos cool season (September-November), but even then environmental temperatures are high. Morning cloud cover usually cleared around noon and air temperature reached $30^{\circ} \mathrm{C}$. Although there was some wind most of the time, the average velocity of $1.0 \mathrm{~m} / \mathrm{s}$ did not lower temperatures by much. The high incident solar radiation load resulted in operative temperatures above body temperature for about $6-9 \mathrm{~h}$ a day for sun exposed pups. Thermoregulatory adjustments are necessary to avoid overheating.

Galapagos fur seal pups apparently have fully developed thermoregulatory abilities at birth. Although $T_{\mathrm{c}}$ varies more during the day than at night, it is regulated around the same average (day $37.7 \pm 0.3$, night $37.5 \pm 0.2^{\circ} \mathrm{C}$ ). The small range of $T_{c}$ is consistent with measurements on mammals with similar body mass (Aschoff 1982), including other seals (Irving et al. 1962; Hubbard 1968; McGinnis 1968). Unlike these studies, the data reported here, were recorded under unmanipulated conditions and reflect responses of seal pups to natural conditions.

A variety of mechanisms allow the pups to maintain thermal balance; some are discussed here.

The most efficient way to avoid overheating is to escape unfavourable temperature regimes. Pups withdraw into the shade of boulders and into lava tunnels, which may be damp. Operative temperature is thus reduced to at least $5^{\circ} \mathrm{C}$ below $T_{\mathrm{c}}$. However, this would still be too high if pups generated and stored excessive heat during periods 
of activity. Behaviour bouts last longer at night, when there is no danger of overheating. Pups, which were dry and active during the hot hours of the day, were usually alone. Their activities consisted mainly of grooming and playing with their flippers or with objects in their immediate surroundings. They were usually performed while lying down or sitting, mainly in the shade, and probably generate less heat than moving about or social interactions. Extended periods of social play between pups usually occurred at dawn and dusk, when it was cool. They only took place during the hot part of the day when pups were wet. Excessive heat is then dissipated, mainly by conductance, to the much cooler water or to wet substrate.

Wetting is a very effective means of temperature regulation. However, it is not always available to pups as it is linked to high tide (Fig. 5). Very young pups have difficulties moving about and cannot cope in strong surf. They need their mothers to take them to the intertidal in their first few days; older pups encounter tide pools on their own.

On rare occasions pups were exposed to high solar radiation. Fur, a good insulator, reduces the rate of heat gain and thus the temperature gradient between it and skin can reach $20^{\circ} \mathrm{C}$. Skin temperatures rose above body temperature when pups were exposed for extended periods, indicating that fur insulation is not sufficient protection against excessive heat. Fur actually impedes heat flow to the environment when the animal's internal temperature is high, whereas flippers dissipate it. The importance of flippers in temperature regulation has been widely documented (Irving et al. 1962; Gentry 1972; Matsuura and Whittow 1972; Tarasoff et al. 1976). They are not covered with fur and are therefore well suited for heat exchange. Their temperature did not correlate with $T_{\mathrm{c}}$. This suggests that blood flow to the flippers is variable. Evaporative cooling had to be used when flipper temperature reached or exceeded $T_{\mathrm{c}}$ and heat flow from the core was no longer possible. Heat dissipation by sweating is limited by the amount of water available.

Body temperature of Galapagos fur seal pups does not follow a daily rhythm. This is extremely rare for mammals (Aschoff 1982). The only other species which lacks a $24 \mathrm{~h}$ cycle is another pinniped, the Northern elephant seal (White and Odell 1971). Body temperature cycle is usually related to activity pattern. The lack of an oscillation in Galapagos fur seal pups' $T_{\mathrm{c}}$ may reflect the temporal organisation of their behaviour. Bouts of activity alternate over $24 \mathrm{~h}$ with sucking or resting bouts of variable duration. Pups may need to be flexible in their behaviour patterns since the female's return from her foraging sojourn is unpredictable and high tide occurs at different times. Short activity bouts during the day shorten the time when heat is generated. This may be an effective way to prevent overheating when heat dissipation is difficult.

This paper focusses on the avoidance of thermal stress by free ranging Galapagos fur seal pups, which experience a very hot climate. The physiological mechanisms of the California sea lion, which lives under similar environmental conditions, are insufficient to maintain body temperature within physiologically tolerable limits (Whittow et al. 1972). This almost certainly also applies to Galapagos fur seal pups. Although they use both behavioural and physiological mechanisms to keep a thermal balance, the former are more important during the day. Pups avoid heat stress by moving to shady spots and reducing activity. Utilisation of cooler microhabitats is a very widely employed strategy by small animals inhabiting desert environments (Bartholomew 1964; Schmidt-Nielsen 1964; Bennett et al. 1984).

Pups depend mainly on shady spots underneath boulders and in caves, but these are limited for the larger adults. Mothers usually enter the sea when thermally stressed. These two modes of thermoregulation lead to conflict between mother and pup, causing further heat stress to the pup. This aspect has been investigated and will be discussed in a forthcoming paper (Limberger in prep).

Acknowledgements. We would like to thank all those who contributed to the work: for critical discussion especially $\mathrm{J}$ Aschoff, $\mathrm{W}$ Wickler, MR Hall, L Gardiner and PI Ward; for field assistance B Ogrisegg-Spazierer, M Taborsky and T Dellinger; for the illustrations and assistance in data analysis B Knauer. This study was supported and financed by the Max-Planck-Gesellschaft and is contribution number 385 from the Charles Darwin Research station.

\section{References}

Arnold W, Trillmich F (1985) Time budget in Galapagos fur seal pups: the influence of the mother's presence and absence on pup activity and play. Behaviour 92:302-321

Aschoff $\mathrm{J}$ (1982) The circadian rhythm of body temperature as a function of body size. In: Taylor CR, Johansen K, Bolis $\mathrm{L}$ (eds) A companion to animal physiology. Cambridge University Press, pp 137-188

Bakken GS (1976) A heat transfer analysis of animals: unifying concepts and the application of metabolism chamber data to field ecology. $J$ Theor Biol 60:337-384

Bartholomew GA (1964) The role of physiology and behavior in the maintenance of homeostasis in the desert environment. Symp Soc Exp Biol 18:7-29

Bartholomew GA, Wilke F (1956) Body temperature in the northern fur seal, Callorhinus ursinus. J Mammal 37:327-337

Bennett A, Huey R, John-Alder H, Nagy K (1984) The parasol tail and thermoregulatory behavior of the Cape ground squirrel Xerus inauris. Physiol Zool 57:57--62

Blix AS, Steen JB (1979) Temperature regulation in newborn polar homeotherms. Physiol Rev 59:285-304

Cane MA (1983) Oceanographic events during E1 Niño. Science 222:1189-1195

Chappell MA, Bartholomew GA (1981) Standard operative temperatures and thermal energetics of the Antelope ground squirrel Ammospermophilus leucurus. Physiol Zool 54:81-95

Colinvaux PA (1984) The Galapagos climate: present and past. In: Perry R (ed) Key Environments - Galapagos. Pergamon Press, Oxford, pp 55-69

Elsner R, Hammond DD, Denison DM, Wyburn R (1977) Temperature regulation in the newborn Weddell seal, Leptonychotes weddelli. In: Lano GA (ed) Adaptations within antaretic ecosystems. Smithsonian Institution, Washington DC, pp 531-540

Gates DM (1981) Biophysical Ecology, Springer, New York

Gentry RL (1972) Thermoregulatory behavior of eared seals. Behaviour 46:73-93

Hubbard RC (1968) Husbandry and laboratory care of pinnipeds. In: Harrison RJ, Hubbard RC, Peterson RS, Rice CE, Schusterman RJ (eds) The behavior and physiology of pinnipeds. Appleton-Century-Crofts, New York, pp 299-358

Irving L, Hart IS (1957) The metabolism and insulation of seals as bare-skinned mammals in cold water. Can J Zool 35:497-511

Irving L, Peyton LJ, Bahn CH, Peterson RS (1962) Regulation of temperature in fur seals. Physiol Zool 35:275-284

Lorenz D (1968) Temperature measurements of natural surfaces using infrared radiometers. Applied Optics 7:1705-1712

Matsuura DT, Whittow GC (1973) Oxygen uptake of the Califor- 
nia sea lion and harbour seal during exposure to heat. Am J Physiol 225:711-715

McGinnis SM (1968) Biotelemetry in pinnipeds. In: Harrison RJ Hubbard RC, Peterson RS, Rice CE, Schusterman RJ (eds) The behavior and physiology of pinnipeds. Appleton-CenturyCrofts, New York, pp 54-68

Porter WP, Gates DM (1969) Thermodynamic equilibria of animals with environment. Ecol Monographs 39:245-270

Rasmusson EM, Wallace JM (1983) Meterological aspects of the El Niño/Southern oscillation. Science 222:1195-1202

Schmidt-Nielsen K (1964) Desert animals : physiological problems of heat and water. Clarendon Press, Oxford

Stevenson RD (1985) The relative importance of behavioral and physiological adjustments controlling body temperature in terrestrial ectotherms. Am Nat (in press)

Tarasoff FJ, Fisher HD (1970) Anatomy of the hindflippers of two species of seals with reference to thermoregulation. Can J Zool 48:821-829
Trillmich F (1984) Natural history of the Galapagos fur seal ( $A r C$ tocephalus galapagoensis, Heller). In: Perry R (ed) Key Environments - Galapagos. Pergamon Press, Oxford, pp 215-223

Trillmich F, Limberger D (1985) Drastic effects of El Niño on Galapagos pinnipeds. Oecologia (Berlin) 67:19-22

White FN, Odell DK (1971) Thermoregulatory behavior of the northern elephant seal, Mirunga angustirostris. J of Mamm 52:758-774

Whittow GC, Ohata CA, Matsuura DT (1971) Behavioral control of body temperature in the unrestrained California sea lion. Comm Behav Biol 6:87-91

Whittow GC, Matsuura DT, Lyn YC (1972) Temperature reguiation in the Californian sea lion Zalophus californianus. Phys Zool 45:68-77

Received October 29, 1985 